\title{
Efeito de métodos de irrigação e do uso de cobertura vegetal sobre o cultivo de repolho em São Luís-MA
}

\author{
Emanoel G de Moura; Karla Danielle A Rezende; Jovenilson C Araujo; Melissa F Castro
}

UEMA, C. Postal 3004, 65054-970 São Luís-MA; E-mails: egmoura@elo.com.br; jovenilsonaraujo@yahoo.com.br; melissacastro01@yahoo.com.br

\section{RESUMO}

Com o objetivo de desenvolver mecanismos que minimizem o estresse da cultura de repolho (Brassica oleracea var. capitata L.) provocado pela alta temperatura do ar em São Luís, MA, instalou-se um experimento em um Argissolo Arênico, no qual foram testados irrigação por aspersão em dois períodos de irrigação diários (às 12 e 18 horas), com e sem cobertura vegetal sobre o solo, e irrigação por sulco com e sem cobertura vegetal sobre o solo. O delineamento experimental foi inteiramente casualizado, com seis repetições. $\mathrm{Na}$ irrigação por aspersão, o horário de irrigação e o uso de cobertura vegetal no solo não afetaram o desenvolvimento das cabeças de repolho (compacidade, comprimento do coração e a massa fresca). Na irrigação por sulco, a compacidade e a massa das cabeças de repolho foram significativamente afetados pelo uso de cobertura no solo, sendo que, nesse sistema a ausência de cobertura no solo resultou em repolhos com cabeça pouco firme e baixa produção de massa fresca (300.9 g), o que originou uma baixa produtividade (7.5 Mg.ha- $\left.{ }^{-1}\right)$. Nas condições do experimento, a irrigação por sulco em solo coberto e a irrigação por aspersão, em solo coberto ou não, possibilitaram melhor desenvolvimento das plantas de repolho.

Palavras-chave: Brassica oleracea var. capitata L.; aspersão; sulco; temperatura.

\section{ABSTRACT}

Effect of irrigation methods and mulching on the cabbage in São Luís, Maranhão, Brazil

In order to develop techniques that minimize heat stress of cabbage crop (Brassica oleracea var. capitata L.) provoked by high air temperatures in São Luís (MA), Brazil, an experiment was carried out in a sandy Alfisol. We compared irrigation by sprinkler in two daily periods of irrigation (12:00 and 18:00 hours) and with and without mulching with furrow irrigation with and without mulching in a completely randomized design with six replications. The schedule of irrigation and the use of mulch didn't affect the development of the cabbage heads in the irrigation by sprinkler treatments, as these factors didn't significantly affect the compactness, the length of the heart or the mass of the cabbage heads. By contrast, in furrow irrigation the compactness and the mass of the cabbage heads were significantly affected by mulching, the absence of mulching resulted in not very firm heads and low fresh mass (mean of $300 \mathrm{~g}$ ), and a low productivity (7.5 Mg.ha- ${ }^{-1}$ ). The furrow irrigation in covered soil and sprinkle in covered or uncovered soil didn't allow better development of the cabbage plants.

Keywords: Brassica oleracea var. capitata L.; sprinkler; furrow; temperature.

(Recebido para publicação em 19 de dezembro de 2005; aceito em 6 de dezembro de 2006)

$\mathrm{A}^{2}$ maioria das espécies de plantas terrestres de folhas tenras é sensível ao calor, sofrendo injúrias a $30-40^{\circ} \mathrm{C}$ (Larcher, 2000). Em repolho, temperaturas elevadas ocasionam a formação de cabeças pouco compactas ou a total ausência de cabeça em algumas variedades (Filgueira, 2002). Isto ocorre provavelmente por ser o repolho uma cultura originalmente de regiões de clima temperado, com melhor desenvolvimento vegetativo na faixa de $15-20^{\circ} \mathrm{C}$ (Filgueira, 1982). Além disso, é uma planta em forma de roseta, com a maior porção da parte aérea próxima ao solo e, portanto, sujeita a maior aquecimento quando comparada a plantas eretas (Larcher, 2000).

O fornecimento de água, em forma ou quantidade, afeta o desenvolvimento, a fitossanidade, a qualidade e a produção das culturas. Isto ocorre porque a irrigação, além de disponibilizar a água para as culturas, aumenta a umidade e diminui a temperatura do ar e do solo (Pires et al., 2000). Imtiyaz et al. (2000), avaliando o rendimento produtivo e o retorno econômico de algumas hortaliças em diferentes níveis de irrigação em relação à evaporação do tanque Classe A, observaram que o rendimento comercial do repolho, em cabeças. $\mathrm{m}^{-2} \mathrm{e}$ a massa das cabeças foram influenciados pelos níveis de irrigação. Os melhores rendimentos, 96,7 e 97,9 Mg.ha-1, foram obtidos com irrigação de $80 \%$ da evaporação. Constataram também que a irrigação com $100 \%$ de reposição da água evaporada reduziu a eficiência do uso da água, pois aumentou consideravelmente o volume aplicado sem melhoria significativa no rendimento comercial.

O uso de cobertura no solo é uma prática recomendada para sistemas orgânicos, devido a benefícios como: (i) melhoria do desempenho das culturas, por contribuir para evitar perdas excessivas de água do solo; (ii) diminuição do impacto da chuva sobre o solo; (iii) diminuição da ação da erosão superficial; (iv) tamponamento das mudanças de temperatura do solo; (v) reposição de nutrientes (vi) desenvolvimento da fauna edáfica, entre outros (Souza \& Resende, 2003). A composição e a densidade da cobertura são importantes aspectos a serem considerados para análise de seus efeitos sobre as culturas. Em teste com diferentes tipos de cobertura na cultura do pimentão, Queiroga et al. (2002) verificaram que a produção de pimentão variou com a qualidade dos materiais utilizados e somente na cobertura com raspa de madeira a produção de pimentão foi menor que no tratamento sem cobertura.

A disponibilidade de híbridos tropicais, no caso do repolho, tem dado ensejo ao surgimento de vários trabalhos 
sobre o seu comportamento em regiões de clima tropical. Em São Luís do Maranhão, Ambrósio \& Moura (1999) trabalhando com avaliação de híbridos experimentais e comerciais de repolho, sob irrigação por aspersão, obtiveram, para o híbrido Astrus, a produtividade de 35,28 Mg.ha-1, com cabeças de $766,98 \mathrm{~g}$ em massa fresca e compacidade firme; tamanho médio do coração de 7,47 cm e 0,60 índice de formato de cabeças. As temperaturas máximas e mínimas registradas durante o experimento oscilaram em torno 28 $33^{\circ} \mathrm{C}$ e $20-23^{\circ} \mathrm{C}$, respectivamente. Araujo et al. (2003), nas mesmas condições, avaliou aquele híbrido, submetido a diferentes níveis de irrigação por sulco, e obtiveram como melhor resultado produtividade de 11,6 Mg.ha-1 e cabeças com massa de 439 g. Esse resultado, pouco expressivo, foi atribuído à baixa eficiência do sistema de irrigação por sulco para a cultura em região de clima quente. Esses resultados, embora tenham contribuído para um maior entendimento do comportamento da cultura do repolho, são ainda insatisfatórios e incomparáveis aos obtidos em outras regiões de clima mais ameno. Fracaro et al. (1999), por exemplo, avaliaram vários cultivares e híbridos de repolho região nordeste do Rio Grande do Sul, e obtiveram para o híbrido Astrus a produção de 48,56 Mg.ha ${ }^{1}$, cabeça com massa fresca de $1.940 \mathrm{~g} \mathrm{e}$ índice de formato de 0,77 .

Com o objetivo de aumentar as alternativas para produção de hortaliças na Ilha de São Luís (MA), este trabalho avaliou a resposta da cultura do repolho a variações do horário e no sistema de irrigação e, ainda, a presença e ausência de cobertura vegetal, em um Argissolo, visando o aumento da eficiência do manejo da irrigação e do uso adequado do solo para o cultivo da hortaliça.

\section{MATERIAL E MÉTODOS}

$\mathrm{O}$ experimento foi conduzido na Universidade Estadual do Maranhão UEMA, em São Luís - MA, situado a $2^{\circ} 33$ 'S e $44^{\circ} 2^{\prime} \mathrm{W}$, no período de outubro a fevereiro de 2003. A temperatura do ar, no período, oscilou entre $33,2^{\circ} \mathrm{C}$ e $26,4^{\circ} \mathrm{C}$, segundo o Núcleo de Meteorologia da UEMA. O solo do local foi classificado como ARGISSOLO VERMELHO-AMARELO Distrófico arênico (EMBRAPA, 1999), com as seguintes características químicas: $\mathrm{pH}=$ 5,$1 ; \mathrm{P}=20 \mathrm{mg} \mathrm{dm}^{-3} ; \mathrm{K}=0,4 ; \mathrm{Ca}=5,0$; $\mathrm{Mg}=5 ; \mathrm{H}+\mathrm{Al}=12\left(\right.$ todos em mmol $\left.\mathrm{dm}^{-3}\right)$ e matéria orgânica $=25 \mathrm{~g} \mathrm{dm}^{-3}$. A calagem e a adubação foram realizadas de acordo com a análise química do solo e a exigência da cultura, segundo recomendações de Raij et al. (1997). Para a calagem foi utilizado cal hidratado, na dosagem de $1 \mathrm{Mg} \cdot \mathrm{ha}^{-1} \mathrm{e}$ a adubação de plantio com $1.375 \mathrm{~kg} \cdot \mathrm{ha}^{-1} \mathrm{de}$ superfosfato simples, $562,50 \mathrm{~kg} \cdot \mathrm{ha}^{-1} \mathrm{de}$ cloreto de potássio e 41.500 litros de esterco de aviário por hectare. Foram realizadas três adubações nitrogenadas complementares de cobertura, com 50 kg.ha- ${ }^{-1}$ de uréia, sendo a primeira aos 30 dias após o transplante e as demais a cada 15 dias. Foram realizadas ainda três aplicações de bórax, via foliar, aos 35 , 50 e 65 dias após a semeadura, na proporção de $1,1 \mathrm{ml} . \mathrm{L}^{-1}$ de água.

A cultivar de repolho utilizada foi o híbrido Astrus (Brassica oleracea var. capitata L.). As mudas foram formadas em 22 bandejas de 200 células, que foram cheias com um substrato constituído de terra preta $(50 \%)$, proveniente de um Argissolo, e esterco de galinha (50\%). Foram acrescentadas $20 \mathrm{~g}$ de superfosfato triplo a cada $40 \mathrm{~L}$ de substrato.

Aos 32 dias após a semeadura, as mudas foram transplantadas para o local definitivo, em espaçamento de 0,80 x $0,50 \mathrm{~m}$, formando parcelas compostas por quatro sulcos de $6,0 \mathrm{~m}$ de comprimento espaçados $0,8 \mathrm{~m}$, resultando em área total de 19,2 $\mathrm{m}^{2}$ por tratamento. $\mathrm{O}$ delineamento experimental foi inteiramente casualizado, por não ser possível dispor os tratamentos sob irrigação por sulco e aspersão em um mesmo bloco, sem que houvesse interferência de um sobre o outro; com quatro repetições e seis tratamentos, sendo quatro irrigados por aspersão e dois irrigados por sulco. Os tratamentos irrigados por aspersão corresponderam à presença e ausência de cobertura vegetal no solo e dois horários de resfriamento diário da cultura, por meio da irrigação por 30 minutos: às 12 e às 18 horas. A irrigação nos quatro tratamentos por aspersão foi realizada aplicando-se uma lâmina d'água de $14 \mathrm{~mm}$ (aproximadamente $140 \mathrm{~m}^{3} \cdot \mathrm{ha}^{-1}$ ) em turno de rega de dois dias, através de microaspersores com vazão de 75 L.h ${ }^{-1}$. Os tratamentos sob irrigação por sulco foram presença e ausência de cobertura vegetal no solo, sendo que ambos recebiam lâmina d'água diária de $10 \mathrm{~mm}$, aplicada por gravidade no início do sulco, através do uso de uma mangueira de 1" de diâmetro ligada a uma cisterna. Como a composição e a densidade da cobertura de solo podem influenciar no desenvolvimento das cultura, o material usado para cobrir o solo, que era composto de restos vegetais provenientes de capinas, foi espalhado uniformemente nas parcelas após o plantio das mudas, de modo a cobrir todo o solo.

Para analise do experimento foram colhidas todas as plantas de uma área útil de $6,4 \mathrm{~m}^{2}$, correspondendo às duas fileiras centrais de cada parcela, desprezadas as bordas. Os parâmetros estudados foram: número de folhas externas basais, diâmetro vertical e horizontal, compacidade, comprimento do coração e massa fresca das cabeças de repolho. A relação entre diâmetro vertical e horizontal gerou o índice de formato de cabeça (quanto mais próximo de 1 (um) mais redonda é a cabeça); já a relação comprimento do coração e diâmetro vertical (relação CC:DV) indica a profundidade do coração (quanto mais próxima de 1 (um) maior é o coração, logo menos desejável). Para a avaliação da compacidade foram atribuídas notas de 0 a 5, sendo: 0 - muito fofa; 2 medianamente fofa; 3 - pouco firme; 4 - firme e 5 - muito firme (Ambrósio \& Moura, 1999). O comprimento do coração foi mensurado com régua milimetrada após corte vertical do repolho.

Os resultados experimentais foram submetidos à análise de variância, com comparação de médias através do teste de Tukey a $5 \%$ de probabilidade.

\section{RESULTADOS E DISCUSSÃO}

Durante a fase de crescimento do repolho a temperatura do ar, no local do 
Tabela 1. Número de folhas basais, índice de formato de cabeça, compacidade, relação CC/ DL, massa fresca e produtividade de repolho (híbrido Astrus) nos diferentes tratamentos ${ }^{1}$. São Luís-MA, UEMA, 2003.

\begin{tabular}{|c|c|c|c|c|c|c|c|}
\hline & \multicolumn{6}{|c|}{ Tratamentos } & \multirow{4}{*}{ CV\% } \\
\hline & \multicolumn{4}{|c|}{ Aspersão } & \multicolumn{2}{|c|}{ Sulco em solo } & \\
\hline & \multicolumn{2}{|c|}{ Solo descoberto } & \multicolumn{2}{|c|}{ Solo coberto } & \multirow{2}{*}{$\begin{array}{l}\text { Solo } \\
\text { desco- } \\
\text { berto }\end{array}$} & \multirow{2}{*}{$\begin{array}{c}\text { Solo } \\
\text { coberto }\end{array}$} & \\
\hline & $12 \mathrm{~h}$ & $18 \mathrm{~h}$ & $12 \mathrm{~h}$ & $18 \mathrm{~h}$ & & & \\
\hline $\mathrm{N}^{\circ}$ folhas basais & $24 a$ & $23 a$ & $24 \mathrm{a}$ & $23 a$ & $23 \mathrm{a}$ & $20 a$ & 10,7 \\
\hline Índice formato & $0,93 a$ & $0,82 \mathrm{~b}$ & $0,87 a b$ & $0,86 a b$ & $0,82 \mathrm{~b}$ & $0,81 \mathrm{~b}$ & 6,2 \\
\hline Compacidade & $4,0 a b$ & $3,9 a b$ & $4,0 \mathrm{ab}$ & $4,1 \mathrm{a}$ & $3,5 b$ & $4,2 \mathrm{a}$ & 8,7 \\
\hline Relação CC/DV & $0,52 \mathrm{a}$ & $0,54 \mathrm{~b}$ & $0,44 \mathrm{a}$ & $0,55 \mathrm{~b}$ & $0,53 a b$ & $0,58 \mathrm{a}$ & 10,8 \\
\hline Massa fresca(g) & $515 a b$ & $525 a$ & $526 a$ & 528 a & $301 \mathrm{~b}$ & $603 a$ & 25,8 \\
\hline Produtividade $\left(\mathrm{Mg} \cdot \mathrm{ha}^{-1}\right)$ & $13 a b$ & $13 a b$ & $13 a b$ & $13 a b$ & $7,5 \mathrm{~b}$ & $15 a$ & 25,9 \\
\hline
\end{tabular}

${ }^{1}$ Médias seguidas de letras iguais, nas linhas, não diferem entre si pelo teste de Tukey (p $<0.05)$; ${ }^{2}$ Hora de início do período diário de resfriamento, de 30 minutos, da cultura.

experimento, variou entre 25 e $33^{\circ} \mathrm{C} . \mathrm{E}$ de acordo com dados obtidos em uma estação meteorologia localizada a menos de $500 \mathrm{~m}$ do local do experimento, as maiores temperaturas durante o dia ocorreram entre 12 e 15 horas, variando de 28 a $33^{\circ} \mathrm{C}$. A temperatura média registrada às 12 horas foi de $29^{\circ} \mathrm{C}$; enquanto às 15 horas, de $31^{\circ} \mathrm{C}$. $\mathrm{O}$ período chuvoso teve início no final de janeiro, quando a cultura já estava em final de ciclo, tendo ocorrido apenas uma chuva em dezembro, registrada em 24,6 mm. A colheita teve início aos 108 dias após a semeadura.

De modo geral, todos os tratamentos proporcionaram o desenvolvimento de uma vegetação basal abundante, sem diferença significativa no que se refere ao número de folhas basais entre os tratamentos (Tabela 1). No mesmo local, sob irrigação por aspersão, Ambrósio \& Moura (1999) obtiveram média de 18 folhas basais para o híbrido Astrus, número inferior ao observado neste trabalho.

A relação diâmetro vertical e horizontal da cabeça de repolho indicou a formação de cabeças levemente achatadas a arredondadas. Os tratamentos sob irrigação por sulco apresentaram as cabeças mais achatadas, sendo que a irrigação em sulco descoberto diferiu estatisticamente da irrigação por aspersão em solo descoberto com resfriamento às $12 \mathrm{~h}$, e originou as cabeças mais arredondadas (Tabela 1).

Tanto o sistema de irrigação quanto à cobertura do solo afetaram a compacidade das cabeças. Isto se verifica quando se compara plantas cultiva- das em solo descoberto, irrigadas por aspersão, com as irrigadas por sulco em solos coberto e descoberto. Na irrigação por sulco a compacidade variou em função da presença ou ausência de cobertura de solo, sendo a compacidade das cabeças de plantas irrigadas por sulco coberto semelhante à compacidade das cabeças cujas plantas foram irrigadas por aspersão com ou sem cobertura de solo. Contudo, quando a irrigação foi feita por aspersão, a presença de cobertura de solo não proporcionou diferença significativa na compacidade (Tabela 1).

A relação CC/DV indica que a irrigação por aspersão com resfriamento ao meio dia, com e sem cobertura de solo, proporcionou a obtenção de cabeças com os menores comprimentos de coração. Em repolho, quanto maior for $\mathrm{o}$ coração, menor será a parte útil, porém, quanto maior o coração e mais compacta for à cabeça, maior será a massa fresca. O tratamento sob irrigação por sulco em solo coberto originou cabeças com maior massa fresca $(603,1 \mathrm{~g}) \mathrm{e}$, consequentemente, melhor compacidade e menor relação CC/DV (Tabela 1). Contudo, em relação à massa fresca, este tratamento só diferiu do tratamento com irrigação por sulco sem cobertura de solo. Na irrigação por aspersão, o horário de resfriamento e a presença de cobertura não influenciaram a produção de massa fresca (Tabela 1). Araujo et al. (2003), trabalhando com várias lâminas d'água na mesma área em irrigação por sulco e sem cobertura do solo, conseguiram com a mesma culti- var, cabeças com apenas $440 \mathrm{~g}$ de massa fresca. Entretanto, Ambrósio \& Moura (1999), avaliando híbridos de repolho, também na mesma área, obtiveram cabeças com massa fresca de 767 g, para o híbrido Astrus sob irrigação por aspersão e com uso de cobertura vegetal. Em Manaus, Cardoso (1998) obteve cabeças com massa fresca de 827,7 g para o mesmo híbrido, em condições em que a temperatura média do ar no período foi de $25,9^{\circ} \mathrm{C}$.

O sistema de irrigação e o horário de resfriamento na irrigação por aspersão não afetaram a produtividade da cultura. No entanto, na irrigação por sulco, o uso de cobertura vegetal no solo teve extraordinário efeito sobre a produtividade da cultura, em condições do experimento. A produtividade de repolho no tratamento sob irrigação por sulco com solo coberto foi o dobro da produtividade nesse sistema sem cobertura de solo (Tabela 1). Segundo Cassol et al. (2004), a presença de resíduos vegetais em cobertura de solo reduz a velocidade de escoamento e eleva a altura da lâmina d'água. Conseqüentemente, há melhoria da uniformidade de distribuição de água no sulco, o que ajuda a explicar o melhor resultado obtido na irrigação por sulco coberto. Em relação à irrigação por aspersão, o uso de pequenos períodos diários de irrigação como mecanismo de resfriamento da cultura, pode substituir o uso de cobertura vegetal no solo.

Mesmo considerando a maior produtividade obtida neste estudo, 15,1 $\mathrm{Mg} \cdot \mathrm{ha}^{-1}$ no tratamento irrigado por sulco com cobertura de solo, esta pode ser considerada baixa, se comparada com outros trabalhos. Entretanto, este resultado pode, em parte, ser explicado pela baixa densidade de plantas utilizada neste experimento (2,5 plantas. $\left.\mathrm{m}^{-2}\right)$. No trabalho de Ambrósio \& Moura (1999), a produtividade chegou a mais de 30 Mg.ha ${ }^{-1}$ em uma densidade de 4,1 plantas. $\mathrm{m}^{-2}$. Além disso, maiores densidades têm a vantagem de proporcionar maior área coberta de solo pelas plantas, o que conseqüentemente impede a incidência direta da luz solar sobre a superfície do solo, podendo contribuir para melhor conservação da umidade e formar um microclima favorável. Essa 
hipótese pode se sustentar no fato de que os últimos autores obtiveram cabeças com mais de $750 \mathrm{~g}$ de massa fresca.

Entre as vantagens da irrigação por aspersão, Scallopi (1986) cita a possibilidade de resfriamento das plantas, que contribui para o controle da temperatura do ar e do solo. Além disso, Bragagnolo \& Mielniczuc (1990) afirmam que o uso de cobertura do solo pode diminuir a temperatura máxima dos $5 \mathrm{~cm}$ da superfície em mais de $1^{\circ} \mathrm{C}$ por tonelada de palha aplicada. Já Khatounian (2001) acrescenta que o uso de cobertura vegetal sobre o solo melhora a conservação da água e ameniza a temperatura para as raízes. Ainda que não tenha sido possível monitorar a temperatura e a umidade na superfície do solo neste experimento, é bastante provável que os melhores resultados atingidos nos tratamentos sob irrigação por sulco, em solo coberto, e sob irrigação por aspersão, tenham ocorrido em decorrência dos efeitos benéficos da irrigação por aspersão e da cobertura no controle da temperatura do ar e do solo e na conservação da umidade do solo, o que pode viabilizar o cultivo do repolho em regiões onde a temperatura do ar é elevada, visto que, originalmente, o repolho é uma cultura de típica de clima temperado, onde o melhor desenvolvimento vegetativo, com produção de cabeça compacta ocorre na faixa de 15$20^{\circ} \mathrm{C}$ (Filgueira, 1982).

Diante dos resultados, conclui-se que, para a região, a irrigação por sulco só é viável para o cultivo de repolho em solo coberto. Já a irrigação por aspersão possibilita um bom desenvolvimento da cultura, produzindo cabeças bem formadas, compactas e peso comercialmente aceitável, independente da presença de cobertura de solo.

\section{REFERÊNCIAS}

AMBRÓSIO FJ; MOURA MCCL. 1999. Avaliação de híbridos experimentais e comercial de repolho para a ilha de São Luís-MA. Pesquisa em Foco 7: 7-16.

ARAUJO JC; MOURA EG; CANTANHÊDE ISL; RESENDE FA. 2003. Produtividade e qualidade do repolho submetido a várias lâminas d'água e turnos de rega na irrigação por sulco fechado. Horticultura Brasileira 21: 346.

ARAUJO JRG; MARTINS MR; SANTOS FN 2004. Fruteiras nativas: ocorrência e potencial de utilização na agricultura familiar do Maranhão. In: MOURA EG (Org). Agroambientes de transição entre o trópico úmido e o semi-árido do Brasil: atributos; alterações; uso na produção familiar. São Luís: UEMA. p. 257-312.

BRAGAGNOLO N; MIELNICZUK J. 1990. Cobertura do solo por palha de trigo e umidade do solo. R. Bras. Ci. Solo 14: 369-374.

CARDOSO MO. 1998. Características de repolhos de verão em ecossistema de terra firme do Amazonas. Horticultura Brasileira 16: 172 175.

CASSOL EA; CANTALICE JRB; REICHERT JM; MONDARDO A.2004. Escoamento superficial e desagregação do solo em entressulcos em solo franco-argilo-arenoso com resíduos vegetais. Pesquisa. Agropecuaria. Brasileira 39: 685-690.

EMBRAPA. 1999. Sistema Brasileiro de Classificação de Solos. Rio de Janeiro: Embrapa Solos. 412p.
FILGUEIRA FA. 1982. R. Manual de olericultura: cultura e comercialização de hortaliças. 2. ed. rev. e ampl. São Paulo: Agronômica Ceres. 357p.

FILGUEIRA FAR. 2002. Novo manual de olericultura: agrotecnologia moderna na produção e comercialização de hortaliças. Viçosa: UFV. 402p.

FRACARO F; SARTORI M; BIZZANI E; GRELMAN E; ECHEVERRIGARAY S. 1999. Comportamento agronômico de cultivares e híbridos de repolho na região Nordeste do Rio Grande do Sul, Brasil. Ciência Rural 29: 465-468.

IMTIYAZ M; MGADLA PN; MANASE SK; CHENDO K; MOTHOBI EO. 2000. Yield and economic return of vegetable crops under variable irrigation. Irrig. Sci 19: 87-93. Disponível http://www.springerlink.com/app/ home/contribution. Acessado em 05 de setembro de 2003.

KHATOUNIAN CA. 2001. A reconstrução ecológica da agricultura. Botucatu: Agroecológica. 348p.

LARCHER. 2000. Walter. Ecofisiologia Vegetal. São Carlos: RiMa. 531p.

PIRES RC de M, SAKAI E, ARRUDA FB, CALHEIROS R de O. 2000. Manejo da irrigação em hortaliças. Horticultura Brasileira 18: 147-157.

QUEIROGA RCF; NOGUEIRA ICC; BEZERRA NETO F; MOURAARB; PEDROSA JF. 2002. Utilização de diferentes materiais como cobertura morta do solo no cultivo de pimentão. Horticultura Brasileira 20: 416-418.

RAIJ B van; CANTARELA H; QUAGGIO JA; FURLANI AMC. 1997. Recomendações de adubação e calagem para o Estado de São Paulo. 2 ed. Campinas: Instituto Agronômico/Fundação IAC. 285p.

SCALOPPI EJ. 1986. Características principais dos sistemas de irrigação. Item 25: 22-27.

SOUZA JL; RESENDE P. 2003. Manual de horticultura orgânica. Viçosa: Aprenda Fácil. $564 \mathrm{p}$. 